\title{
BULLYING NO AMBIENTE ESCOLAR, BEM-ESTAR E QUALIDADE DE VIDA: RELATO DE EXPERIÊNCIA DE PESQUISAS SOBRE A TEMÁTICA
}

Sandra Mara Mayer ${ }^{1}$, Heloisa Elesbão ${ }^{2}$

${ }^{1}$ Universidade de Santa Cruz do Sul - UNISC, Santa Cruz do Sul, RS, Brasil.

${ }^{2}$ Universidade Federal de Santa Maria - UFSM, Santa Maria, RS, Brasil.

E-mail: smmayer@unisc.br

Acesso DOI: http://dx.doi.org/10.34059/ciejop.2019v28i1-8

Introdução: Todos sabemos que a violência escolar repetitiva, denominada bullying, não é um problema recente, entretanto, a frequência com que esses casos vêm aumentando causa preocupação. A partir disso, e dos amparos legais garantidos pelo estado e união, entendemos a necessidade do desenvolvimento de estudos que contemplem a referida temática, com o intuito de identificar os locais e formas de ocorrência e envolvimento com o bullying, objetivando garantir as pessoas envolvidas um amparo em relação as consequências negativas do bullying, visando remediar possíveis prejuízos a seu bem-estar e sua qualidade de vida. A partir disso, o presente trabalho tem como objetivo relatar a experiência vivenciada ao longo do desenvolvimento de pesquisas acerca da temática bullying no ambiente escolar. Metodologia: O presente trabalho de natureza qualitativa no qual desenvolveremos um relato de experiência acerca das vivências e experiências obtidas no desenvolvimento de pesquisas acerca da temática bullying no ambiente escolar. Resultados: Para a realização de nossas pesquisas fazemos uso do questionário de Olweus adaptado por Mayer. O questionário é composto por quatro blocos: o primeiro bloco refere-se aos dados de identificação, como por exemplo, idade, turma; os demais blocos referem-se a perguntas de múltipla escolha, nas quais são realizados questionamentos referentes a presença do bullying no ambiente escolar. Posteriormente a aplicação do questionário e tabulação dos dados, buscamos retornar as instituições participantes da pesquisa para realizarmos a apresentação dos dados, com o intuito de propormos ações que venham a prevenir, reduzir e remediar as consequências de envolvimento com esse fenômeno, tendo como princípio garantir o bem-estar e a qualidade de vida dos sujeitos. Conclusão: A partir disso, compreendemos a necessidade de estudos que tenham como foco mapear e caracterizar as formas como o bullying vem se configurando, com o intuito de buscarmos possíveis mecanismos de prevenção e remediação desse fenômeno.

Palavras-chave: Bullying. Violência Escolar. Pesquisas. 